\title{
PRODUÇÃO DE (IN)VISIBILIDADES: MULHERES NEGRAS E POLÍTICAS PÚBLICAS DE SAÚDE
}

\author{
BAIRROS, A. K. ${ }^{1}$, HILLESHEIM, B. ${ }^{2}$, SILVA, M. L. ${ }^{3}$ \\ PALAVRAS-CHAVE: Raça. Gênero. Políticas Públicas. Mulheres Negras.
}

\begin{abstract}
RESUMO
As mulheres negras estão em um lugar desfavorecido na sociedade, expostas a diferentes tipos de violência, incluindo o que diz respeito ao acesso à saúde. Partindo deste pressuposto, realizou-se uma análise das políticas públicas de saúde voltadas para as mulheres negras, visando compreender de que forma busca-se dar conta das demandas especificas dessa população. Como metodologia, analisaram-se três documentos elaborados pelo Ministério da Saúde, onde se observou o contexto em que as palavras "mulheres negras", "mulheres brancas", "população negra", "raça" e "cor", se inserem. Problematizou-se, a partir dos estudos culturais, sobre se as políticas públicas de saúde estão produzindo visibilidade ou invisibilidade em relação às mulheres negras, partindo do entendimento de que, quando um determinado grupo é mais vulnerável em relação aos outros, não nomeá-lo tende a ser mais uma forma de exclusão. Através da análise dos documentos, elencaram-se duas categorias de análise, onde, na primeira, buscou-se discutir sobre identidade, diferença e branquitude, visto que a identidade branca, nos documentos, permanece invisível. Após, reflete-se sobre a relação da cor com o conceito de vulnerabilidade social.
\end{abstract}

\section{(IN)VISIBILITIES PRODUCTION: BLACK WOMEN AND PUBLIC HEALTH POLICIES}

\author{
KEYWORDS: Race. Genre. Public Policies. Black Women.
}

\begin{abstract}
Black women are in a disadvantaged place in society, exposed to different types of violence, including access to health. Based on this hypothesis, an analysis of public health policies focused at black women was made, aiming to understand how the specific demands of this population are handle by the government. As a methodology, three documents prepared by the Health Ministry were analyzed, where the words "black women", "white women", "black population", "race" and "color" were included. From the cultural studies, it has been questioned if public health policies are producing visibility or invisibility regarding black women, based on the understanding that when one group is more vulnerable than others, to not name it tends to be another form of exclusion. Through the analysis of the documents, two categories were presented, where, in the first, it was discussed identity, difference and whiteness, since white identity remains invisible in the documents. In sequence, it was made a reflection about the relation of color with the concept of social vulnerability.
\end{abstract}




\section{INTRODUÇÃO}

Se pensarmos em uma pirâmide social, dividida em quatro níveis, teríamos o homem branco compondo o topo, seguido pela mulher branca, o homem negro e, por fim a base, composta pela mulher negra. Portanto, percebe-se que ser mulher em nossa sociedade é estar em uma posição desfavorável, porém ser mulher e negra é estar em uma posição ainda mais inferiorizada. Segundo o "Mapa da Violência 2015: homicídio de mulheres no Brasil" há dados que evidenciam que a maior porcentagem das mulheres negras brasileiras vive nas periferias, em situação de extrema pobreza, assim como estão duas vezes mais expostas à violência.

Como estratégia para dar conta dessas e outras demandas da população em diferentes âmbitos, contamos com a elaboração de políticas públicas, que são desenvolvidas pelo poder público a fim de garantir os direitos descritos na Constituição Federal de 1988. Porém, questiona-se sobre como é realizado o enfoque de gênero e raça na elaboração das políticas públicas, já que para dar conta das questões citadas, é necessário haver um olhar direcionado para as especificidades das mulheres negras, ou seja, para a perspectiva da interseccionalidade entre gênero e raça.

Diante destas questões, o artigo tem como objetivo realizar uma análise sobre as políticas públicas de saúde voltadas para a mulher negra visando compreender de que forma busca-se dar conta das demandas especificas dessa população. Para tanto, lançamos mão da análise de três documentos elaborados pelo Ministério da Saúde que possuem enfoque de gênero e raça. Estes documentos são intitulados como: "Política Nacional de Atenção Integral à Saúde da Mulher" (2004), Perspectiva da Equidade no Pacto Nacional Pela Redução da Mortalidade Materna e Neonatal: A Saúde das Mulheres Negras" (2005) e por fim, a "Política Nacional de Saúde Integral da População Negra: Uma Política do SUS" (2017).

0 artigo está organizado em três seções. Na primeira, problematizamos articulação entre políticas públicas e a perspectiva interseccional (gênero e raça). Na segunda, apresentamos uma descrição da metodologia utilizada na pesquisa, seguida pelas discussões das categorias analíticas, cujas bases se assentam nos Estudos Culturais, como é o caso das questões relativas à identidade. Por fim, apresentamos as considerações finais da pesquisa que, esperamos, possam contribuir para que se qualifiquem e se repensem as práticas de cuidado das mulheres negras.

\section{AS POLÍTICAS PÚBLICAS E A INTERSECCIONALIDADE ENTRE GÊNERO E RAÇA}

As políticas públicas são ações desenvolvidas pelo Estado a fim de assegurar e colocar em prática os direitos que estão previstos na Constituição Federal. Podemos resumi-las como sendo um campo do conhecimento que busca "colocar o governo em ação", analisando essas intervenções e, se necessário, propondo mudanças no que está posto. (SOUZA, 2006).

$\mathrm{Na}$ Constituição Federal o direito à saúde é considerado princípio indispensável para o ser humano, portanto é de competência do Poder Público zelar por sua efetivação. Este direito está descrito na Constituição Federal de 1988, no "art. 196. A saúde é direito de todos e dever do Estado, garantido mediante políticas sociais e econômicas que visem à redução do risco de doença e de outros agravos e ao acesso universal e igualitário às ações e serviços para sua promoção, proteção e recuperação" (BRASIL, 1988).

A Constituição também assegura ao Estado o dever de visar à diminuição do risco de doenças, promovendo saúde, proteção e recuperação através do acesso universal à saúde. Importante ressaltar que esse direito é universal e igualitário, sendo assim, o acesso deve ser igual para todos. (BRASIL, 1988). 
Partindo de uma concepção ampla do direito à saúde e do dever do Estado na garantia desse direito, a implantação do Sistema Único de Saúde (SUS) ocorre após a promulgação da Lei Orgânica da Saúde (lei n. 8.080, de 19 de setembro de 1990, complementada pela lei n. 8.142, de 28 de dezembro de 1990), incorporando espaços e instrumentos para democratização e compartilhamento do processo de decisão e da gestão do sistema de saúde. Salienta-se, entretanto, a Constituição da República Federativa do Brasil, promulgada em 5 de outubro de 1988, como pilar fundamental de sua criação, a partir da qual foi possível traçar os princípios e diretrizes do SUS: Universalidade; Equidade; Integralidade; Descentralização e Participação Social. (GIOVANELLA, 2012).

Até 1970 , os cuidados em relação à saúde das mulheres nas políticas públicas eram voltados à procriação, o período gestacional e puerperal, ou seja, tinha-se a visão da mulher enquanto sujeito destinado à maternidade. Partindo da necessidade de aprimorar essas ações, atuando em diferentes ciclos da vida da mulher, houve a união de interesses entre o movimento sanitário e o movimento feminista, o que resultou na criação Programa de Assistência Integral à Saúde da Mulher (PAISM) no ano de 1983. O PAISM transforma-se em um marco na história das políticas públicas, surgindo para propor uma nova reflexão sobre o fazer em relação à saúde da mulher dentro dos serviços de saúde. A partir do reconhecimento da diferença de gênero é que as políticas públicas implementam ações especificas dirigidas às mulheres. A inclusão de métodos contraceptivos nas políticas públicas de saúde torna-se um grande avanço diante da visão tida anteriormente. Através desta ação passa-se a reconhecer a "mulher como sujeito ativo no cuidado de sua saúde, atendendo-se, assim, as questões referentes aos diretos reprodutivos". (MEDEIROS, GUARESCHI, 2009. pág. 40).

Djamila Ribeiro (2017), escritora, ativista e negra, questiona o discurso recorrente de que as políticas públicas "devem ser para todos":

\footnotetext{
Mas quem são esses "todos" ou quantos cabem nesses "todos"? Se mulheres, sobretudo negras, estão num lugar de maior vulnerabilidade social justamente porque essa sociedade produz essas desigualdades, se não se olhar atentamente para elas, se impossibilita o avanço de modo mais profundo. Melhorar o índice de desenvolvimento humano de grupos vulneráveis deveria ser entendido como melhorar o índice de desenvolvimento humano de uma cidade, de um país. E, para tal, é preciso focar nessa realidade, ou como as feministas negras afirmam há muito: nomear. Se não se nomeia uma realidade, sequer serão pensadas melhorias para uma realidade que segue invisível. A insistência em falar de mulheres como universais, não marcando as diferenças existentes, faz com que somente parte dessas mulheres seja visto. (RIBEIRO, pág. 41).
}

Silveira e Nardi (2014) compreendem que a violência contra a mulher é um evento que ocorre mundialmente. Através de entrevistas realizadas com alguns juízes, os resultados obtidos apontam que estes profissionais não percebem a relação entre gênero, raça e etnia como interferência ao acesso a justiça, o que, no entendimento dos autores, se mostra como um silenciamento destas questões. Os autores destacam que temáticas como a violência de gênero são complexas, exigindo aprofundamento teórico bem como sensibilidade daqueles que atuam com estas questões. 0 gênero caracteriza-se como sendo a primeira forma de poder sobre os corpos. A classe, o gênero e a raça são os grandes marcados sociais pelos quais a subjetividade é produzida. Segundo Foucault (1995) apud Silveira e Nardi (2014):

As relações de poder constituem o campo de possibilidades dos modos de subjetivação no interior dos quais se articulam os processos de resistência (intrínsecos a essa compreensão de poder). Para esse autor, o conceito de produção de subjetividade compreende a vida como efeito de um campo de possibilidades marcado por jogos de verdade que potencializam determinadas formas de nos constituirmos como sujeitos Nessa perspectiva, o sujeito não é visto como uma unidade psicológica "autônoma", mas como um ser inscrito numa trama histórica que lhe oferece as condições para a construção de si no registro do social. (SILVEIRA, NARDI, pág. 3). 
0 termo "interseccionalidade" é utilizado para se referir à soma de fatores opressores. No caso das mulheres negras, a interseccionalidade se dá entre a raça e o gênero, que são duas categorias que apontam para a vulnerabilidade, portanto não podem ser pensadas de forma separada, já que ambas são fatores excludentes. 0 gênero por si só é um fator que gera violência, porém "atinge de forma mais grave aquelas que combinam mais de uma opressão". (RIBEIRO, 2018, pág. 133). Pensar as consequências que estas combinações produzem, é uma forma de proporcionar outras formas de existência para essa população (RIBEIRO, 2018).

Silva (1998) realizou uma análise, questionando diretamente mulheres que integram o Movimento Negro, buscando compreender de que forma as mulheres negras constituem-se enquanto cidadãs em uma sociedade que as descrimina. Diante dos dados obtidos, aponta que as mulheres negras lutam, entre outras questões, contra a invisibilidade a qual estão submetidas e também para que seus direitos sejam garantidos através das políticas públicas. As entrevistadas relatam o racismo e o machismo que enfrentam diariamente, o que a autora questiona:

\footnotetext{
"Diante de tudo isso, é de se perguntar como pode a grande maioria das mulheres negras no Brasil ser sadia. A tendência manifesta entre elas à pressão alta tem causa na constituição biológica, em hábitos nutricionais ou no racismo e no machismo que determinam as relações entre as pessoas? Como não ter a saúde afetada, tendo em vista o estado de pauperização em que vivem, a precariedade das moradias e as condições de higiene dos bairros onde residem? Até quando a falta de informação e apoio à mulher pobre, na sua maioria negra, para decidir e controlar o número de filhos levará à prática do aborto, nas piores condições de higiene e segurança e a custo muitas vezes da vida?" (SILVA, 1998, s/p).
}

Através de um estudo sobre os níveis de acesso aos serviços preventivos de saúde entre mulheres brancas e mulheres negras na Bahia, Goes e Nascimento (2013) perceberam que o racismo institucional e a desigualdade racial caracterizam-se como uma barreira para as mulheres negras. Quando falamos em desigualdades sociais estamos nos referindo às situações que colocam alguns grupos em posição desfavorecida, diminuindo seu acesso aos direitos e oportunidades. Isso não ocorre de forma individual, mas sim reflete uma forma de funcionamento cultural, onde os indivíduos se organizam através de valores sociais construídos historicamente. Cri (2006) apud Goes e Nascimento (2013) define o racismo institucional como sendo um fracasso das organizações, devido à falha destes em proporcionar um atendimento igualitário para todos os indivíduos, independentemente de sua cor ou raça. Salienta que o racismo institucional é responsável por colocar em desvantagem determinados grupos raciais, diminuindo o acesso destes aos direitos básicos como, por exemplo, a saúde.

\section{METODOLOGIA}

A presente pesquisa utilizou-se do método de produção conhecido como Análise Documental, o qual foi articulado com os Estudos Culturais. A proposta da análise documental é selecionar, de forma criteriosa, documentos e a partir deles organizar categorias de análise que estejam em consenso com o problema da pesquisa. (PIMENTEL, 2001). Foram selecionados três documentos oficiais elaborados pelo Ministério da Saúde que correspondem com o tema da pesquisa, como colocamos acima.

O documento referente à "Política Nacional de Atenção Integral à Saúde da Mulher" (PNAISM) foi criado pelo Ministério da Saúde no ano de 2004 com o objetivo de garantir os direitos humanos das mulheres através do enfoque de gênero. Seus princípios norteadores são a integralidade e a promoção de saúde, buscando reduzir o número de doenças por causas preveníveis. As ações também buscam contemplar grupos que, historicamente, 
não são atingidos pelas políticas públicas, buscando reconhecer suas necessidades especificas. Dentro deste grupo incluem-se as mulheres negras. (BRASIL, 2004).

Já a "Perspectiva da Equidade no Pacto Nacional Pela Redução da Mortalidade Materna e Neonatal: A Saúde das Mulheres Negras" foi divulgada no ano de 2005, também pelo Ministério da Saúde. Este documento se propõe a destacar algumas especificidades da mulher negra na área da saúde, buscando apontar estratégias que respeitem as singularidades dessa população. Pressupõe os direitos sexuais e reprodutivos como direitos humanos que devem ser compreendidos a partir de suas demandas especificas. Ressalta que os indicadores de saúde devem considerar não só o enfoque de gênero nas ações em saúde da população feminina, mas também o quesito raça. (BRASIL, 2005).

No ano de 2017 o Ministério da Saúde divulga a $3^{\mathrm{a}}$ edição do documento referente à Política Nacional de Saúde Integral da População Negra (PNSIPN), instituída através da Portaria nº 992 de 13 de maio de 2009. Essa política reconhece o racismo como sendo um dos determinantes das condições de saúde de homens e mulheres negras, associando as injustiças a que estão submetidos aos processos culturais da história do nosso país. Sendo assim, o documento busca, através de suas diretrizes e objetivos, promover a equidade em saúde. (BRASIL, 2017).

A partir da leitura dos três documentos, separou-se em quadros o contexto em que as palavras "mulheres negras", "mulheres brancas", "raça", "cor" e "população negra” se encontravam. 0 objetivo desta investigação foi o de compreender o que está associado a cada palavra: o sentido que há e/ou qual o contexto foi possível para aquele termo. Buscou-se entender se, de alguma forma, há lugares pré-estabelecidos para cada uma. Analisar o contexto em que estas palavras são utilizadas é importante para pensarmos se as políticas públicas de saúde estão produzindo visibilidade ou invisibilidade em relação às mulheres negras, partindo do entendimento de que, quando um determinado grupo é mais vulnerável em relação aos outros, não nomeá-lo tende a ser mais uma forma de exclusão.

As categorias elencadas a partir da análise documental foram problematizadas à luz dos Estudos Culturais. Essa área caracteriza-se como um campo aberto, utilizando-se de diferentes disciplinas e teorias que se interseccionam, buscando "compreender a complexidade e as contradições de uma vasta série de formas culturais insertas na vida cotidiana e, em diferentes dimensões, objetivam entender como esses produtos e instituições servem não só como instrumento de dominação, mas, também, como fonte de resistência e mudança”. (ESCOSTEGUY, 2003, pág. 67). 0 que difere os Estudos Culturais de outras disciplinas tradicionais é seu caráter político. Suas análises não têm como objetivo a neutralidade, mas sim a produção como forma de intervir no cotidiano social e político das populações que estão desvantagens devido às relações de poder. (GUARESCHI, MEDEIROS, BRUSCHI, 2003).

\section{RESULTADOS}

\subsection{A identidade das mulheres negras}

Através da análise documental, percebe-se que todas às vezes em que as palavras "mulheres brancas" são utilizadas é em comparação com as "mulheres negras". Esse fato demonstra que as mulheres brancas só são mencionadas quando é necessário falar dos efeitos da cor na vida das mulheres negras, marcando a diferença. A ausência da cor, quando se fala somente em "mulheres" indica sua condição de brancas, o que nos mostra a necessidade de repensar o que é ser branco em nossa sociedade. 
Durante toda a história, o branco é tido como o padrão de ser humano, o sujeito ideal, o que o coloca em uma posição de privilégio até os dias atuais. Esse estereótipo mantém os que não se encaixam nesse perfil em uma posição inferior, como é o caso das pessoas negras. Através da reflexão a respeito da branquitude, é que se pode reconhecer o lugar de privilégio que os brancos ocupam, sendo esse um passo necessário para que se descontrua a hierarquia que foi produzida ao longo do tempo. 0 conceito de branquitude refere-se ao questionamento consciente por parte dos brancos sobre os efeitos do racismo na sua constituição enquanto sujeitos brancos, buscando o reconhecimento e a conscientização de uma supremacia branca. (JESUS, 2012). Segundo, Piza (2005), a "branquitude não diz respeito aos discursos ingênuos que afirmam: "somos todos iguais perante Deus, ou perante as leis"; ao contrário, reconhece que "alguns são mais iguais do que os outros" e reverte o processo de se situar no espaço dos mais iguais para reivindicar a igualdade plena e de fato, para todos". (PIZA, 2005, p. 07).

Segundo Silva (2000), a identidade pode ser compreendida como sendo aquilo que eu "sou", enquanto a diferença é o que o "outro é". A identidade e a diferença não existem à priori, não são constituintes de uma natureza pré-existente. São definições produzidas no âmbito social, fabricadas a partir das relações culturais e ocorrem através do processo de linguagem. Mesmo a identidade sendo referência para a existência da diferença, uma só faz sentido quando relacionada com a outra, tornando-se assim, indissociáveis. Nesse sentido, a identidade das mulheres brancas só precisa ser afirmada porque existem mulheres que não são brancas, caso contrário, se vivêssemos em um mundo homogêneo, essa afirmação de não seria necessária. Portanto, quando se utiliza as palavras "mulheres brancas" nas comparações, o que está imposto é a afirmação de que essas mulheres "não são negras". Essa demarcação significa que as mulheres brancas são o que as mulheres negras não são (SILVA, 2000) Diante disso, percebe-se que "a identidade é marcada pela diferença, mas parece que algumas diferenças - neste caso entre grupos étnicos - são vistas como mais importantes que outras". (WOODWARD, 2000, pág. 11).

A diferença ao mesmo tempo em que, por vezes, é necessária, também pode ser perigosa. Com base na linguagem, compreendendo-a como uma forma de funcionamento cultural, entende-se que a diferença é importante, pois é através dela que existem os significados. Tomando como exemplo a comparação existente nos documentos, é possível compreender o significado de "mulheres negras" porque podemos fazer o contraste com as "mulheres brancas", que são o oposto. Porém, o risco da diferença está no reducionismo das oposições, "por exemplo, naquilo que chamamos de fotografia em preto e branco não há, na verdade, um puro "preto" e "branco", mas vários tons de cinza" (HALL, 2016, pág. 154). Portanto, percebe-se que as diferenças estruturais ficam invisibilizadas. Além disso, o binarismo comumente possui um polo dominante, devido às relações de poder que, nesse caso, são as mulheres brancas. (HALL, 2016).

Grada Kilombola, escritora, psicóloga e artista multidisciplinar portuguesa, que trabalha com temas como gênero e raça, concedeu entrevista à Ribeiro (2018), durante vinda para o Brasil. Ao ser questionada sobre a universalidade na qual os indivíduos brancos geralmente se colocam, Grada refere que a diferença só existe quando há uma norma, apontando que é a partir dela que os outros tornam-se diferentes, já que não fazem parte dessa norma. Portanto, defende que o mito de que a discriminação ocorre devido aos sujeitos negros serem diferentes, deve ser desconstruído, já que é a discriminação que os torna diferentes. Neste sentido, a artista questiona: "como pessoas negras, muitas vezes, somos referidos como diferentes. E eu coloco a questão: diferente de quem? Quem é diferente? Tu és diferente de mim ou eu sou diferente de ti?". (RIBEIRO, 2018, pág. 111). 
As mulheres negras não estão inclusas nos debates sobre racismo, pois estes espaços são ocupados pelos homens negros. Nos discursos sobre gênero, os sujeitos em questão são as mulheres brancas. Da mesma forma ocorre com as discussões sobre classe: a raça não faz parte. Refletir sobre o feminismo pode nos mostrar este apagamento das mulheres negras, já que, ao lutar, por exemplo, para que mulheres tenham o direito a ingressarem no mercado de trabalho e não apenas ocupem os espaços domésticos, invisibiliza-se o fato de que as mulheres negras já compõem, exaustivamente, estes espaços. Portanto, "as mulheres negras não sofrem as consequências por fazerem parte de duas categorias inferiorizadas, mas por estarem excluídas delas" (ROSA, 2018, pág. 13).

Há muito tempo as mulheres negras lutam contra a universalização do que é ser mulher, problematizando o feminismo que acaba por englobar apenas as mulheres brancas. É necessário romper com esse padrão, pois "a insistência em falar de mulheres como universais, não marcando as diferenças existentes, faz com que somente parte dessas mulheres seja vista" (RIBEIRO, 2017, pág. 41). A autora aponta consequências na insistência dessa visão homogênea, de homem/mulher, o que acaba por produzir efeitos na existência das mulheres negras, podendo ser percebidos através dos resultados encontrados nos documentos analisados:

Quadro 1 - Mulheres brancas e mulheres negras

\begin{tabular}{|c|c|}
\hline Contexto & Página \\
\hline $\begin{array}{c}\text { Taxa de analfabetismo das mulheres negras é o dobro se comparada a das } \\
\text { mulheres brancas. }\end{array}$ & 50 \\
\hline $\begin{array}{c}\text { Mulheres negras possuem menor acesso aos serviços de saúde de boa } \\
\text { qualidade e possuem maior risco de contrair e morrer de determinadas do que as mulheres brancas }\end{array}$ & 50 \\
\hline $\begin{array}{c}\text { Mulheres brancas tem mais acesso à atenção ginecológica do que as mulheres } \\
\text { negras. }\end{array}$ & 50 \\
\hline $\begin{array}{c}\text { Incidência de parto cesárea em BH foi de 28,4\% para mulheres negras e 48,1\% } \\
\text { para mulheres negras foi 11,1\% }\end{array}$ & 51 \\
\hline $\begin{array}{c}5,1 \% \text { de mulheres brancas não receberam anestesia no parto normal. Enquanto } \\
\text { 82\% das mulheres brancas não foram informadas sobre a importância do pré- } \\
\text { natal, em comparação a 76,6\% das mulheres negras }\end{array}$ & 51 \\
\hline $\begin{array}{c}\text { Sinais de parto: 73,1\% das mulheres brancas foram informadas em relação a } \\
62,5 \% \text { das mulheres negras }\end{array}$ & 51 \\
\hline $\begin{array}{c}\text { Aleitamento: 77,7\% das mulheres brancas foram orientadas, enquanto 62,5\% } \\
\text { das mulheres negras tiveram orientação. }\end{array}$ & 51 \\
\hline $\begin{array}{c}\text { Puderam ter acompanhantes: 46,2\% das brancas e 27,0\% das negras } \\
\text { negras é cinco vezes maior que em mulheres brancas. No Brasil, segundo Souza } \\
\text { (1995), também é alta a incidência e reincidência de miomas em mulheres }\end{array}$ & 51 \\
\hline
\end{tabular}

Fonte: Política Nacional de Atenção Integral à Saúde da Mulher: Princípios e diretrizes, 2004

Essas comparações entre mulheres brancas e mulheres negras vão ao encontro da teoria de que as mulheres negras são "o Outro do Outro", conforme Grada Kilomba, em nítido dissenso à Simone de Beauvoir. Para Grada, por não ser só em relação ao gênero que as mulheres negras são invisibilizadas, mas também em relação à raça, ocupando um lugar à margem das duas categorias, acaba sendo muito difícil a convivência em uma sociedade hierarquicamente branca e masculina. 0 ato de falar só é possível quando uma voz é ouvida, o 
que define quem tem direito a essa fala. Portanto, a voz do "Outro do Outro" ocupa um lugar de não pertencimento, resultando no silenciamento das questões das mulheres negras. A luta das mulheres negras é justamente para quebrar este vácuo silencioso e reivindicar seu direito de fala que, neste caso, também é reivindicar pelo direito à vida. (RIBEIRO, 2017).

\subsection{Raça e vulnerabilidade}

Através dos contextos onde se inserem as palavras "população negra”, observa-se que, em sua maioria, estas são utilizadas para relacionar cor à vulnerabilidade social. A palavra vulnerabilidade, segundo o Dicionário Aurélio, é um substantivo feminino que pode significar uma característica, uma particularidade ou então um estado que é vulnerável. Como sinônimos de vulnerabilidade, o dicionário apresenta as seguintes palavras: fragilidade, delicadeza e insegurança. (FERREIRA, 2010). Percebe-se que a palavra vulnerabilidade carrega um significado negativo, associado à ideia de fragilidade, perdas e, muitas vezes, ao risco. Outra definição de vulnerabilidade relaciona este termo a grupos de indivíduos cujos recursos são insuficientes para acenderem socialmente. (CRUZ, HILLESHEIM, 2016). Portanto,

Pode-se dizer que o termo se refere a pessoas que apresentam alterações tanto no sentido de alguma situação de 'normalidade' física quanto de seu ciclo de vida ou condição social, gerando uma compreensão de que pertencem a grupos 'deficitários' ou que, de algum modo, sofreram prejuízos. Além disso, os descritos incluem uma dimensão ética, visando à proteção e defesa desses grupos. Há ainda uma vinculação estreita entre vulnerabilidade e risco, sendo que, em muitos estudos, são usados como sinônimos. (CRUZ, HILLESHEIM, pág. 300).

Vejamos alguns recortes dos quadros:

Quadro 2 - População negra

\begin{tabular}{|c|c|}
\hline Contexto & Página \\
\hline $\begin{array}{c}\text { Hipertensão arterial é mais frequente, se inicia mais precocemente e apresenta } \\
\text { uma evolução mais grave na população negra. }\end{array}$ & 9 \\
\hline A diabetes tipo II - não insulino - dependente é prevalente na população negra & 10 \\
\hline $\begin{array}{c}\text { Anemia falciforme é a doença genética mais comum no Brasil e apresenta } \\
\text { maior prevalência na população negra }\end{array}$ & 11 \\
\hline
\end{tabular}

Fonte: Perspectiva da Equidade no Pacto Nacional Pela Redução da Mortalidade Materna e Neonatal: A Saúde das Mulheres Negras, 2005

Quadro 3 - População negra

\begin{tabular}{|c|c|}
\hline Contexto & Página \\
\hline $\begin{array}{c}\text { Nossa história, construída sobre as bases da desigualdade, reservou } \\
\text { para a população negra o lugar das classes sociais mais pobres e de condições } \\
\text { mais precárias. }\end{array}$ & 5 \\
\hline $\begin{array}{l}\text { Precocidade dos óbitos, nas altas taxas de mortalidade materna e infantil, na } \\
\text { maior prevalência de doenças crônicas e infecciosas, bem como nos altos } \\
\text { índices de violência urbana incidem sobre a população negra. }\end{array}$ & 5 \\
\hline $\begin{array}{c}\text { A resistência dos movimentos sociais vem denunciando a indignidade das } \\
\text { condições de vida da população negra, traduzindo-as em reivindicações por } \\
\text { políticas públicas que reduzam a desigualdade e ampliem a equidade do acesso } \\
\text { aos bens e serviços públicos. }\end{array}$ & 5 \\
\hline $\begin{array}{c}0 \text { risco de morte por homicídios é maior nas populações negras, independente } \\
\text { de sexo. }\end{array}$ & 14 \\
\hline
\end{tabular}




\begin{tabular}{|c|c|}
\hline $\begin{array}{c}\text { A população negra tem 70\% mais chance de morrer por tuberculose que as } \\
\text { pessoas brancas. }\end{array}$ & 15 \\
\hline $\begin{array}{c}\text { Consenso entre estudiosos acerca das doenças e agravos prevalentes na } \\
\text { população negra. }\end{array}$ & 15 \\
\hline $\begin{array}{c}\text { Importância em considerar o racismo para uma análise adequada das condições } \\
\text { sociais e da saúde da população negra. }\end{array}$ & 15 \\
\hline $\begin{array}{c}\text { Condições históricas trazem consigo o preconceito e a discriminação, afetando a } \\
\text { população negra de todas as camadas sociais. }\end{array}$ & 16 \\
\hline
\end{tabular}

Fonte: Política Nacional de Saúde Integral da População Negra: Uma Política do SUS, 2013

Diante disso, quando um dos documentos afirma que "as populações expostas a precárias condições de vida estão mais vulneráveis e vivem menos." (BRASIL, 2004, pág. 12), é necessário compreender que vulnerabilidade é um conceito complexo, que não está relacionado somente com a pobreza, mas sim com diferentes elementos que constituem os sujeitos como, por exemplo, "à inserção e estabilidade no mercado de trabalho, à fragilidade de suas relações sociais e à regularidade e qualidade de acesso aos serviços públicos ou outras modalidades de proteção social”. (CRUZ, HILLESHEIM, 2016, pág. 302).

Outro fato que pode ser observado nos itens que compõe esses quadros e que foram retirados dos documentos analisados é o que diz respeito a maior prevalência de determinadas doenças na população negra, como hipertensão arterial, diabetes tipo II e anemia falciforme. Além de fatores biológicos, Souza (2000) aponta diferentes causas que justificam essa realidade, como a qualidade de vida relacionada às condições materiais e psicossociais dessa população. Em um estudo sobre a incidência de miomas uterinos em mulheres negras na cidade de São Paulo, concluiu-se que essas têm menos acesso aos serviços de saúde por não possuírem registro na carteira de trabalho, o que não lhes garante direitos quando há necessidade de se ausentar do ambiente de trabalho, fazendo com que percam o dinheiro que receberiam no dia, mesmo apresentando atestado médico. Além da predisposição genética para o desenvolvimento do mioma uterino, a precariedade de suas vidas, como o exemplo citado acima, atua como fator psicossocial no aparecimento de tumores. (SOUZA, 2000). Nesse sentido:

Você já se perguntou alguma vez porque tantas mulheres negras parecem sentir raiva? Ou por que caminhamos como se carregássemos tijolos nas nossas bolsas e fôssemos golpear e maldizer uma amiga simplesmente por ter derrubado um chapéu? Isso acontece porque o stress é a bainha das nossas roupas, está grudado aos nossos cabelos, impregnado em nosso perfume e pintado em nossas unhas. 0 stress vem de sonhos adiados, de sonhos reprimidos; vem de sempre estarmos por baixo, de nunca sermos consideradas bonitas, de não nos valorizarem, de tirarem vantagem de nós; vem de sermos mulheres negras na América branca. Por quanto tempo você acha que pode prender a respiração sem ser asfixiada? Sim, as mulheres negras se suicidam! Nós nos matamos quando paramos de sorrir, quando tomamos drogas para abafar a dor de ser negra; quando, no desespero de ter "alguém", permitimos que nosso companheiro ou companheira nos violente física e mentalmente; quando permitimos que privilégios de classe, renda, cor, aparência ou preferência sexual nos dividam; quando mês após mês choramos sozinhas sem ter com quem desabafar. Estamos estressadas. (ADISA, pág. 114).

Já as palavras "cor" e, por vezes, "raça" sugerem, em grande parte dos contextos onde se encontram, sobre a importância do preenchimento deste campo nos sistemas de saúde:

Quadro 4 - Cor

\begin{tabular}{|l|c|}
\hline \multicolumn{1}{|c|}{ Contexto } & Página \\
\hline $\begin{array}{l}\text { Introdução: Necessidade de incorporar questões relativas à raça/etnia, ou seja, o } \\
\text { "quesito cor" na saúde, visando a que todos os indicadores de saúde considerem } \\
\text { estas variáveis. }\end{array}$ & 5 \\
\hline Subnotificação do quesito "cor" na maioria dos sistemas de informação da área & 7 \\
\hline
\end{tabular}




\begin{tabular}{|l|c|}
\hline $\begin{array}{l}\text { da saúde, dificulta análise mais consistente sobre a saúde da mulher negra no } \\
\text { Brasil }\end{array}$ & \\
\hline $\begin{array}{l}\text { No item: Morte materna e mulheres negras. Fala sobre os poucos dados em } \\
\text { relação à mortalidade materna com recorte étnico/racial. O “quesito cor”, } \\
\text { apesar de constar na Declaração de Óbito, muitas vezes não é preenchido ou a } \\
\text { informação não corresponde à realidade. }\end{array}$ & 10 \\
\hline $\begin{array}{l}\text { A inclusão do "quesito cor" nos sistemas de informações e documentos do SUS } \\
\text { consta no documento “Compromissos do Ministério da Saúde para com a Saúde } \\
\text { da Mulher” de 28/05/2003 }\end{array}$ & 16 \\
\hline $\begin{array}{l}\text { Fala sobre a importância de sensibilizar e capacitar os profissionais sobre a } \\
\text { importância da informação “quesito cor” }\end{array}$ & 17 \\
\hline $\begin{array}{l}\text { “Quesito cor" deve ser por auto declaração e com base na classificação racial no } \\
\text { IBGE: preto(a), branco(a), pardo(a), indigena, amarelo(a) }\end{array}$ & 17 \\
\hline
\end{tabular}

Fonte: Perspectiva da Equidade no Pacto Nacional Pela Redução da Mortalidade Materna e Neonatal: A Saúde das Mulheres Negras, 2005

Quadro 5 - Raça

\begin{tabular}{|c|c|}
\hline Contexto & Página \\
\hline $\begin{array}{c}\text { Introdução: Necessidade de incorporar questões relativas à raça/etnia, ou seja, o } \\
\text { “quesito cor” na saúde, visando a que todos os indicadores de saúde considerem } \\
\text { estas variáveis. }\end{array}$ & 5 \\
\hline $\begin{array}{c}\text { Item: Sensibilização e capacitação de profissionais de saúde. Incluir nas } \\
\text { capacitações de profissionais o conteúdo sobre diferenciais étnicos/raciais nas } \\
\text { condições de vida e na saúde da população. }\end{array}$ & 16 \\
\hline
\end{tabular}

Fonte: Perspectiva da Equidade no Pacto Nacional Pela Redução da Mortalidade Materna e Neonatal: A Saúde das Mulheres Negras, 2005

Barbujani (2007) apud Rosa (2018) refere que o termo "raça”, utilizado como definição para grupos humanos, não encontra respaldo nas áreas biológicas. Trata-se de um conceito que se difundiu a partir do século $\mathrm{XV}$, após as viagens marítimas intercontinentais, onde o termo era utilizado com base nas diferenças, classificando e inferiorizando grupos a partir do padrão homem, branco e europeu. As relações de poder que seguem produzindo efeito ainda hoje encontram fundamento nessa época em que foram, por tanto tempo, legitimadas. Portanto, o conceito de "raça" não está ligado ao biológico, mas sim às relações do cotidiano. A questão racial não implica na afirmação da não existência de outras tonalidades de pele, mas demonstra a importância em problematizar porque a cor, e não outras características, são utilizada para legitimar a identidade dos indivíduos. (ROSA, 2018).

Através da atuação do movimento negro, a presença da categoria raça/cor nos sistemas de saúde tem sido utilizada como forma de desconstruir o mito da democracia racial, partindo da justificativa de que a não utilização desse campo colabora para o ocultamento das informações, impedindo que se obtenha conhecimento sobre o s efeitos da discriminação racial. (ADORNO, ALVARENGA, VASCONCELLOS, 2004).

\section{CONSIDERAÇÕES FINAIS}

Através da análise de políticas públicas de saúde voltadas para as mulheres negras, buscou-se compreender de que forma se dá a interseccionalidade entre gênero e raça, bem como problematizar a forma como se constituem os discursos em torno da saúde das mulheres negras. Foi possível perceber que, em todas as vezes que os documentos utilizam as palavras "mulheres brancas", são para compara-las com as "mulheres negras". Através deste fato, problematizou-se sobre a marcação da identidade das mulheres brancas quando é 
para falar das desvantagens da cor, demonstrando que essa identidade branca permanece invisível por ser hegemônica. Portanto, refletiu-se sobre o fato de que a identidade se faz pela diferença. As palavras "população negra", na maioria das vezes em que aparece nos documentos, estão associadas com vulnerabilidade, o que justifica a inclusão das mulheres negras nas políticas públicas de saúde como uma categoria separada. Já as palavras "raça" e "cor" aparecem nos contextos onde se fala sobre a importância de marcar estes quesitos em todos os sistemas de saúde.

Werneck (2016) reflete sobre o descaso com que a saúde da mulher negra é tratada, pontuando que este assunto não faz parte dos currículos dos cursos de graduação e pós-graduação da área da saúde, o que torna muito baixo o número de produções científicas. Este fato que a autora pontua em sua pesquisa, pode ser percebido através do baixo número de publicações encontradas através do estado da arte, tornando este um assunto de extrema relevância e urgência em ser trabalhado. Entende-se que essa problematização se faz necessária para que não se continue colaborando com a marginalização desta população que há tempos vem sendo marcada pelo descaso.

Os efeitos da desigualdade racial não são compatíveis com os princípios do SUS. Segundo os documentos analisados, a média de mulheres negras que tiveram acesso à anestesia, que foram submetidas a abortos inseguros, que receberam informações pós-parto, entre outros, está muito abaixo do percentual das mulheres brancas. A saúde, como citado ao longo desta pesquisa, constitui-se como sendo direito de todos os indivíduos, portanto é necessário que a questão racial seja norteadora das políticas públicas de saúde, para assim contribuir com a desconstrução da cor e do gênero como questões que colocam alguns indivíduos acima dos outros. Nesse sentido, falar sobre as opressões vivenciadas pela população negra não deve ser considerada uma tarefa que os não brancos não possam desempenhar. Pelo contrário, é necessário ocupar o lugar de privilégio que ser branco proporciona e dar voz ao povo que foi historicamente discriminado pelos nossos antecedentes e que continua sofrendo as consequências disso todos os dias. Não basta não ser racista, é necessário atuar junto, sendo antirracista e incluir os negros nas pesquisas realizadas dentro das universidades.

\section{REFERÊNCIAS}

ADISA, Opal Palmer; Balançando sob a luz do sol: Stress e Mulher Negra. In. WERNECK, Jurema; MENDONÇA, Maisa; WHITE, Evelyn C. (Org.). O livro da saúde das mulheres negras: nossos passos vêm de longe. Rio de Janeiro: Pallas: Criola, 2000.

ADORNO, Rubens de C.F.; ALVARENGA, Augusta Thereza de; VASCONCELLOS, Maria da Penha. Quesito cor no sistema de informação em saúde. Estud. av., São Paulo, v. 18, n. 50, p. 119-123, Abr. 2004. Disponível em <http://www.scielo.br/scielo.php?script=sci_arttext\&pid=S0103-40142004000100011\&lng=en\&nrm=iso>. Acesso em 27 Nov. 2018.

BRASIL. Perspectiva da equidade no pacto nacional pela redução da mortalidade materna e neonatal. Atenção à saúde das mulheres negras. Brasília. Ministério da Saúde. 2005.

Saúde. 2004.

Política Nacional de Atenção Integral à Saúde da Mulher: princípios e diretrizes. Brasília. Ministério da

Política Nacional de Saúde Integral da População Negra. Brasília. Ministério da Saúde. 2017.

CRUZ, Lilian Rodrigues da; HILLESHEIM, Betina. Vulnerabilidade Social. In: FERNANDES, Rosa M. Castilhos; HELLMANN, Aline (org.). Dicionário Crítico: Política de Assistência Social no Brasil. Porto Alegre: Ed. UFRGS, 2016.

BRASIL, Constituição Federal. República Federativa do Brasil. Texto compilado, 1988. Disponível em:

<http://www.planalto.gov.br/ccivil_03/Constituicao/ConstituicaoCompilado.htm> Acesso em 08 Out 2018. 
ESCOSTEGUY, Ana Carolina D.; Os Estudos Culturais e a constituição de sua identidade. In: GUARESCHI, Neuza Maria de Fátima; BRUSCHI, Michel (Org.). Psicologia social nos estudos culturais: perspectivas e desafios para uma nova psicologia social. Petrópolis: Vozes, c2003. 238 p. (Coleção Psicologia social).

FERREIRA, Aurélio Buarque de Holanda. Dicionário Aurélio da língua portuguesa. 5. ed. Curitiba: Positivo, 2010. I, 2222 p.

GIOVANELLA, Lígia (org.). Políticas e Sistema de Saúde no Brasil. 2. Ed. Rio de Janeiro, RJ: Fiocruz, 2012.

GOES, Emanuelle Freitas; NASCIMENTO, Enilda Rosendo do. Mulheres negras e brancas e os níveis de acesso aos serviços preventivos de saúde: uma análise sobre as desigualdades. Saúde debate, Rio de Janeiro, v. 37, n. 99, p. 571-579, Dez. 2013 . Disponível em: <http://www.scielo.br/scielo.php?script=sci_arttext\&pid=S010311042013000400004\&Ing=en\&nrm=iso>. Acesso em 23 de Out de 2018.

GUARESCHI, Neuza Maria de Fátima; MEDEIROS, Patrícia Flores de; BRUSCHI, Michel Euclides; Psicologia Social e Estudos Culturais: rompendo fronteiras na produção do conhecimento. In: GUARESCHI, Neuza Maria de Fátima; BRUSCHI, Michel (Org.). Psicologia social nos estudos culturais: perspectivas e desafios para uma nova psicologia social. Petrópolis: Vozes, c2003. 238 p. (Coleção Psicologia social).

HALL, Stuart. Cultura e representação. Rio de Janeiro: Apicuri, 2016. 259 p.

JESUS, Camila Moreira. Branquitude x Branquidade: uma análise conceitual do ser branco. Anais do III Encontro Baiano de Estudos Culturais, 2012.

MEDEIROS, Patricia; GUARESCHI, Neuza. 2009. Políticas públicas de saúde da mulher: a integralidade em questão. Revista Estudos Feministas, Florianópolis. Jan.-abr. 2009. № 17 (1), p. 31-48.

PIMENTEL, Alessandra. 0 método da análise documental: Seu uso na pesquisa historiográfica. Cadernos de Pesquisa, 114, 179-195, nov. 2001.

PIZA, Edith. Adolescência e racismo: uma breve reflexão. An. 1 Simp. Internacional do Adolescente May. 2005. Disponível em: <http://www.proceedings.scielo.br/scielo.php?pid=MSC0000000082005000100022\&script=sci _arttext>. Acesso em 26 Nov. 2018.

RIBEIRO, Djamila. 0 que é lugar de fala?. Belo Horizonte: Letramento, c2017. 111 p. (Feminismos plurais). . Quem tem medo do feminismo negro?. 1. ed. São Paulo: Companhia das Letras, c2018. 148 p.

ROSA, Rita de Cassia Quadros da. "Todas as mulheres são brancas e todos os negros são homens": gênero, "raça" e a constituição normativa das mulheres negras no Brasil. Dissertação (Mestrado em Educação). Universidade de Santa Cruz do Sul. Santa Cruz do Sul, 2018.

SILVA, Petronilha Beatriz Gonçalves e. "Chegou a hora de darmos a luz a nós mesmas": Situando-nos enquanto mulheres e negras. Cad. CEDES, Campinas, v. 19, n. 45, p. 7-23, Jul 1998. Disponível em <http://www.scielo.br/scielo.php?script=sci_arttext\&pid=S010132621998000200002\&lang=pt> Acesso em 18 Nov. 2018.

SILVA, Tomaz Tadeu et al. A produção social da identidade e da diferença. In: SILVA, Tomaz Tadeu da; HALL, Stuart; Woodward, Kathryn (Org.). Identidade e diferença: a perspectiva dos estudos culturais. Petrópolis: Vozes, 2000.

SILVEIRA, Raquel da Silva; NARDI, Henrique Caetano. Interseccionalidade gênero, raça e etnia e a lei Maria da Penha. Psicol. Soc., Belo Horizonte , v. 26, n. spe, p. 14-24, 2014. Disponível em:

<http://www.scielo.br/pdf/psoc/v26nspe/03.pdf> Acesso em 18 de Abril de 2018.

SOUZA, Celina. Políticas públicas: uma revisão de literatura. Sociologias, Porto Alegre, v. 8, n. 16, p. 20-45, jul./dez. 2006.

SOUZA, Vera Cristina de; A prevalência de miomas uterinos em mulheres negras: As dificuldades e avanços na coleta e análise dos dados com recorte racial. In. WERNECK, Jurema; MENDONÇA, Maisa; WHITE, Evelyn C.

(Org.). 0 livro da saúde das mulheres negras: nossos passos vêm de longe. Rio de Janeiro: Pallas: Criola, 2000. 
WAISELFISZ, Julio. Jacobo. Mapa da violência 2015: homicídio de mulheres no Brasil. Brasília, 2015. Disponível em: <https://www.mapadaviolencia.org.br/pdf2015/MapaViolencia_2015_mulheres.pdf.> Acesso em 18 de Abril de 2018.

WERNECK, Jurema. Racismo institucional e saúde da população negra. Saude soc., São Paulo, v. 25, n. 3, p. 535549, Set. 2016. Disponível em <http://www.scielo.br/pdf/sausoc/v25n3/1984-0470-sausoc-25-03-00535.pdf> Acesso em 23 de Out de 2018.

WOODWARD, Kathryn. Identidade e diferença: uma introdução teórica e conceitual. In: SILVA, Tomaz Tadeu da; HALL, Stuart; Woodward, Kathryn (Org.). Identidade e diferença: a perspectiva dos estudos culturais. Petrópolis: Vozes, 2000. 